\title{
Transfusion Practices Committee of a public blood bank network in Minas Gerais, Brazil
}

Ricardo Vilas Freire de Carvalho

Stela Brener ${ }^{1}$

Angela Melgaço Ferreira ${ }^{1}$

Marcele Cunha Ribeiro do Valle

Helio Moraes-Souza ${ }^{1,2}$

'Fundação Centro de Hematologia e Hemoterapia de Minas Gerais - Fundação Hemominas, Belo Horizonte, MG, Brazil ${ }^{2}$ Universidade Federal do Triângulo Mineiro UFTM, Uberaba, MG, Brazil
Conflict-of-interest disclosure:

The authors declare no competing financial interest

Submitted: 11/22/2011

Accepted: 9/20/2012

Corresponding author:

Helio Moraes de Souza

Fundação Centro de Hematologia e Hemoterapia de Minas Gerais - Fundação

HemominasAlameda Ezequiel Dias, 321. Bairro Santa Efigênia

30.130-110 Belo Horizonte, MG, Brazil

helio.moraes@dcm.uftm.edu.br

www.rbhh.org or www.scielo.br/rbhh
Objective: This study aimed to verify the performance of blood transfusion committees in transfusion services linked to the public blood bank network of the state of Minas Gerais.

Methods: A cross-sectional observational study was conducted between 2007 and 2008 using questionnaires and proficiency tests to evaluate the reporting and investigation of transfusion reactions comparing transfusion services with and without transfusion committees in the public transfusion services of the state of Minas Gerais.

Results: Nineteen of Hemominas own transfusion services and 207 that contracted the services of the foundation located in 178 municipalities were visited between 2007 and 2008. Established transfusion committees were present in $63.4 \%$ of the services visited. Transfusion incidents were reported by $53(36.8 \%)$ transfusion services with transfusion committees and by eight $(9.6 \%)$ without transfusion committees $(p<0.001)$ with $543(97.5 \%)$ and $14(2.5 \%)$ notifications, respectively. Of the reported transfusion incidents, $40(75.5 \%)$ transfusion services with transfusion committees and only two (25\%) of those without transfusion committees investigated the causes.

Conclusion: The incidence of notification and investigation of the causes of transfusion reactions was higher in transfusion services where a transfusion committee was present. Despite these results, the performance of these committees was found to be incipient and a better organization and more effective operation are required.

Keywords: Blood transfusion; Blood safety; Professional staff committees; Blood banks

\section{Introduction}

Concerns regarding blood transfusion-related risks exist in most countries, especially those of Europe and North America ${ }^{(1-7)}$. Likewise, in the international literature, there are numerous observations of the importance of hemovigilance in transfusions ${ }^{(1-5,8-11)}$. However, in Brazil, there are few studies on this subject in particular about the impact of the implementation of transfusion committees (TCs) in relation to hemovigilance and transfusion safety ${ }^{(12,13)}$.

The monitoring, detection, screening and treatment of transfusion reactions, as well as preventive measures, used as strategies to minimize the occurrence of these adverse events, have been mandatory in Brazil since 2004.

In Brazil, better control measures in the selection of blood donors were established after 1980 with the advent of AIDS and its social impact. In addition, remunerated blood donations were prohibited in order to maximize the safety of donor and recipient ${ }^{(3,10)}$. Despite major progress in Brazilian transfusion therapy, particularly in respect to measures to prevent the transmission of infectious diseases through donated blood, strategies for the detection and prevention of transfusion reactions are still needed.

Blood transfusion policies started to be effectively discussed, designed and implemented in Brazil only after 2000 when the establishment of multidisciplinary TCs was proposed for health centers that used transfusion therapy ${ }^{(14,15)}$. The objective of these TCs was to detect, investigate, treat and prevent transfusion reactions, i.e., to monitor blood transfusion practices in order to minimize transfusion-related risks, as well as to rationalize the use of blood products ${ }^{(15)}$. These measures became mandatory in 2004 with the publication of Board Resolution No. 153 (RDC 153) of the Brazilian national health surveillance agency, ANVISA, which determines that "Health centers where a blood transfusion service is available need to establish a multidisciplinary TC in which one representative of the therapy service must participate"(16). In view of this scenario, the objectives of the present study were to determine the existence of TCs at blood transfusion services linked to the public blood bank network of Minas Gerais, to evaluate their impact on aspects related to transfusion safety, and to provide data that contribute to the elaboration of strategies aimed at improving blood transfusion surveillance in the state and in Brazil.

\section{Methods}

A cross-sectional, observational study was conducted. This study was part of the project "Transfusion safety: evaluation of the physical and operational infrastructure of 
transfusion services of the public blood bank network of the State of Minas Gerais" developed by Hemominas. Data were collected between July 2007 and August 2008.

All blood transfusion services and contractors providing blood products to Hemominas were investigated using specific questionnaires based on the current legislation and applied in loco. Using an evidence-based approach, the instrument was tested and validated in a pilot study, showing high reproducibility and overall agreement.

Systematic cluster sampling was used for the collection of data regarding registries, requests, production and release of blood and blood products, and records of the occurrence of adverse reactions.

Transfusion reactions can be defined as any adverse event resulting from blood transfusion. These reactions are traditionally classified according to etiology as infectious or non-infectious and immunological or non-immunological, and according to the time of occurrence as immediate or late ${ }^{(17)}$.

Evidence of the existence of a TC included the existence of meeting protocols, administrative actions of the committee, and records of events, classes, lectures and standardization. First a descriptive analysis was performed to characterize the profile of transfusion services with and without a TC. Differences between the two groups were evaluated using Pearson's or Fisher's chi-square test. A technical criterion was adopted to select the variables to be analyzed according to current legislation ${ }^{(16)}$. Variables that are not formally described in the legislation but, when present, are considered to be "measures of good practice" were also included.

The EpiData (version 3.1) program was used for data entry and SPSS Statistics 17.0 and SPSS Decision Trees for statistical analysis. The "Decision Tree" methodology consists of a multivariate analysis based on charts that illustrate decision rules ${ }^{(18)}$. These trees start with a node that contains all observations of the sample. Next, the data branch into mutually exclusive subsets that become increasingly more homogenous in relation to the response variable. The existence of a TC was defined as the response variable and factors related to its performance were defined as explanatory variables. The CHAID algorithm (Chi-square Automatic Interaction Detector) was used and a $\mathrm{p}$-value $\leq 0.05$ was defined as the stopping criterion. The risk estimate of incorrect classification that compares the value observed for the sample and the value predicted by the model was used to evaluate the goodness of fit of the model.

\section{Results}

A total of 226 transfusion services and those that contracted the services of Hemominas, located in 178 municipalities, which performed 33,283 transfusions in the month prior to the visit and application of the questionnaires, were studied.

Evidence of a TC was obtained in $144(63.6 \%)$ transfusion services, which performed 29,197 transfusions, whereas no TC was present in $82(36.3 \%)$ performing 4,086 transfusions. A total of 557 transfusion incidents had been registered over the previous 12 months representing approximately $0.15 \%$ notifications/year. These adverse reactions occurred in $53(36.8 \%)$ transfusion services with a TC and in eight $(9.6 \%)$ without a TC (p < 0.001), with 543 $(97.5 \%)$ and $14(2.5 \%)$ notifications, respectively. Regarding the investigation of the causes of the transfusion incidents, $40(75.5 \%)$ of the transfusion services with a TC that notified these incidents, but only two $(25 \%)$ of the other services, investigated their causes. The number of notifications of transfusion reactions was 422, including $419(99.3 \%)$ by transfusion services with a TC and three $(0.7 \%)$ by services without at TC. Blood component bags were screened in cases of transfusion reactions at $24(10.6 \%)$ transfusion services, 20 of which $(83.3 \%$ ) had a TC. Deletions on transfusion request forms were identified in $64(44.4 \%)$ and $27(32.9 \%)$ transfusion services with and without a TC, respectively $(\mathrm{p}=0.160)$, incorrect identification of the recipient sample in $86(59.7 \%)$ and $54(65.9 \%$ $\mathrm{p}=0.361)$, and the transfusion record book signed by the responsible person in $71(49.3 \%)$ and $29(35.4 \%)$, respectively $(\mathrm{p}=0.042)$.

Individual transfusion charts of the recipients were kept at $38(26.4 \%)$ of the transfusion services with a TC and at nine $(11 \%)$ services without a TC $(p=0.006)$. These charts were

Table 1 - Comparison of transfusion services of the public blood bank network of Minas Gerais with an established transfusion committee and those without in respect to current legislation and good technical practices

\begin{tabular}{|c|c|c|c|c|c|}
\hline \multirow[t]{2}{*}{ Parameter } & \multicolumn{2}{|c|}{$\begin{array}{l}\text { Transfusion Services with } \\
\text { evidence of a transfusion } \\
\text { committee }(n=144)\end{array}$} & \multicolumn{2}{|c|}{$\begin{array}{l}\text { Transfusion Services without } \\
\text { evidence of a transfusion } \\
\text { committee }(\mathbf{n}=\mathbf{8 2})\end{array}$} & \multirow[t]{2}{*}{ p-value } \\
\hline & $\mathbf{n}$ & $\%$ & $\mathbf{n}$ & $\%$ & \\
\hline Existence of forms for the notification of transfusion reactions & 133 & 92.4 & 62 & 75.6 & $<0.001$ \\
\hline Notification of transfusion reactions & 53 & 36.8 & 8 & 9.6 & $<0.001$ \\
\hline Investigation of the causes of transfusion reactions & 40 & 27.8 & 2 & 2.4 & $<0.001$ \\
\hline Update of the transfusion chart & $37^{\mathrm{a}}$ & 97.4 & $7^{\mathrm{b}}$ & 77.8 & 0.031 \\
\hline \multicolumn{6}{|l|}{ Good technical practices } \\
\hline Technician's signature in the transfusion book & 71 & 49.3 & 29 & 35.4 & 0.042 \\
\hline Deletions in transfusion requests & 64 & 44.4 & 27 & 32.9 & 0.16 \\
\hline
\end{tabular}

${ }^{\mathrm{a}} \mathrm{n}=38,{ }^{\mathrm{b}} \mathrm{n}=9,{ }^{\mathrm{c}} \mathrm{n}=113,{ }^{\mathrm{d}} \mathrm{n}=60$ 
Q19 Is there evidence of an existing trnsfusion Committee?

$$
\begin{array}{|lrr|}
\hline \text { Cat. } & \% & \mathrm{n} \\
\hline \text { Yes } & 63.72 & 144 \\
\text { No } & 36.28 & 82 \\
\hline \text { Total } & 100.00 & 226 \\
\hline
\end{array}
$$

Q21 Were causes of transfusion incidents investigated last year? p-value $=0.0000 ;$ Chi-square $=22.1711 ; \mathrm{df}=1$

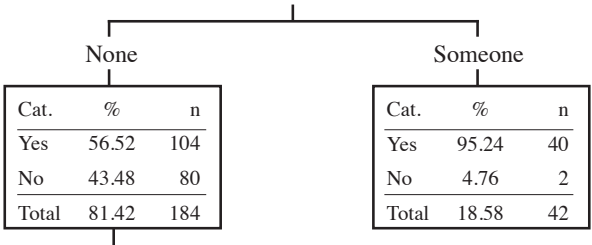

Q12 Is there documentation of notification of transfusion reactions? $\mathrm{p}$-value $=0.0051 ;$ Chi-square $=7.8428 ; \mathrm{df}=1$

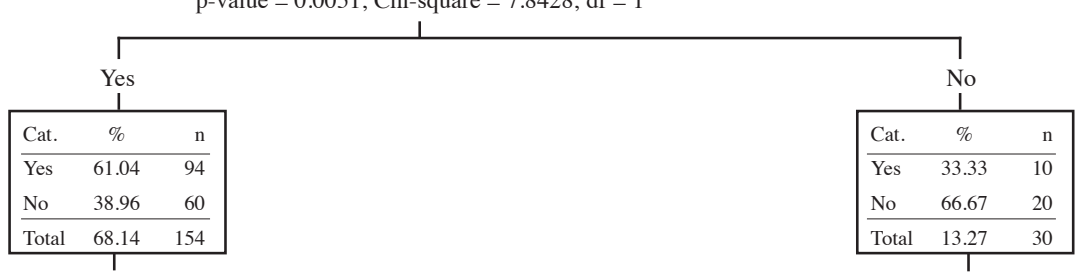

Q21 Does the qualified technician sign the release of the red blood cell bag? $\mathrm{p}$-value $=0.0222 ;$ Chi-square $=5.2310 ; \mathrm{df}=1$

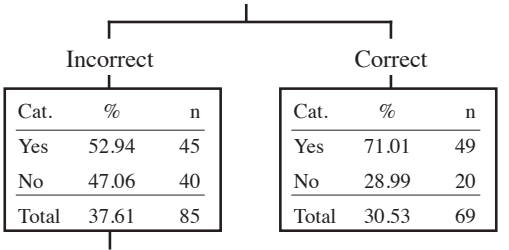

Q7 Does the transfusion procedures log have an opening document? p-value $=0.0195 ;$ Chi-square $=5.4545 ; \mathrm{df}=1$

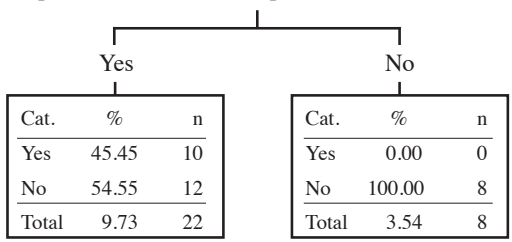

Q14.2 Samples - first name, surname (no abbreviations) $\mathrm{p}$-value $=0.0384 ;$ Chi-square $=4.2888 ; \mathrm{df}=1$

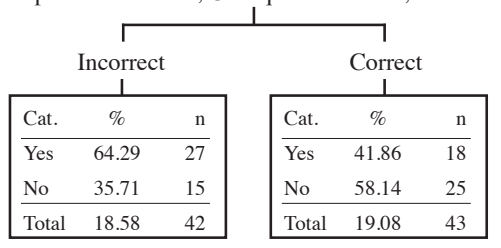

df: degrees of freedom
Figure 1 - Multivariate decision tree analysis of factors associated with the presence of a transfusion committee at transfusion services of the public blood bank network of Minas Gerais, 2007-2008. The tree demonstrates a predominance of compliance with mandatory technical standards and good practices for services that possess a transfusion committee, including the investigation of the causes of transfusion reactions, existence of forms for the notification of transfusion reactions, signature of the person responsible in the transfusion book, presence of an opening statement in the transfusion book, and correct identification of the recipient samples. updated after each transfusion at $37(97.4 \%)$ and seven $(77.8 \%)$ of these services, respectively $(\mathrm{p}=0.031)$.

A laboratory technician who performed pre-transfusion tests was present in $34(30.1 \%)$ transfusions services with a TC and in $18(30 \%)$ without a TC $(\mathrm{p}=0.99)$.

The results of this study are summarized in Table 1 . Figure 1 shows the predominance of compliance with mandatory technical standards and good practices for transfusion services that possess a TC, including the investigation of the causes of transfusion reactions, existence of forms for the notification of transfusion reactions, signature of the person responsible in the transfusion book, presence of an opening statement in the transfusion book and correct identification of the recipient samples.

\section{Discussion}

In the present study, we observed that, despite legal and contractual requirements, a significant proportion of the transfusion services linked to Hemominas do not possess a TC. In addition, the rate of non-compliance with current legislation and/or good practices was high even for those services in which a TC was implemented, suggesting ineffective implementation. Corroborating this assertion, the authors suggest that hospital TCs should have a major role in hemovigilance, allowing transfusion incidents related to the transfusion of blood components to be notified, their consequences assessed and appropriate actions in relation to their prevention to be taken. In addition, the indications of blood products should always be reviewed by the TC, thereby optimizing usage ${ }^{(12)}$. Within the context of hemovigilance, the TC is a major contributor to promote measures to provide greater safety to transfusion recipients ${ }^{(12,19)}$. The highest rate of compliance was observed regarding the existence of forms for the notification of transfusion reactions, with compliance being significantly higher in transfusion services with a TC compared to those without a TC. However, despite the better performance of transfusion services with a TC, the number of notifications of transfusion reactions and the investigation of their causes were very 
low considering the number of transfusions performed in the previous year. The results of the present study are in contrast to the international literature which reports a frequency of transfusion reactions higher than $2 \%{ }^{(20)}$ suggesting that a significant number of reactions are not notified even by transfusion services that possess a TC. Thus, the true rates of transfusion reactions in Brazil are unknown and it is believed that most episodes are not identified $^{(15,21)}$. The ANVISA Bulletin of Hemovigilance in 2010 estimated, based on the rate of transfusion reactions of France, that about $69.5 \%$ of transfusion incidents were not reported in 2009 (ranging from $97.2 \%$ in the Midwest to $60.5 \%$ in the Southeast), while acknowledging an improvement with the implementation of the System of Health Surveillance Notifications (NOTIVISA) as a tool for hemovigilance. Evidence of this improvement is the observed reduction in the rate of underreporting over the last three years as evaluated by the Bulletin $(81.6 \%$ in 2007 versus $69.5 \%$ in 2009). Moreover, the Bulletin corroborates the findings of this study, showing that in 2009 the rate of underreporting in Minas Gerais was $92.2 \%$. It is important to consider that the monitoring, detection, tracking and management of transfusion reactions as well as prevention measures have been mandatory in Brazil since $2004^{(16)}$.

Another aspect of non-compliance with the current legislation was the incorrect identification of samples. Although transfusion services with a TC showed a slightly better performance than those without a TC, incorrect identification was observed in approximately two-thirds of the transfusion services studied. Several investigations have shown that errors in sample identification, especially those that occur outside the transfusion service, are one of the commonest causes of switching blood products and, consequently, of severe hemolytic reactions ${ }^{(13,20)}$. Therefore, the failures documented here may compromise the safety of blood transfusions, especially because of the risk of incorrect identification of the patient during the infusion of blood products.

Two other aspects of non-compliance with the legislation were also identified: the absence of an individual transfusion chart and the failure to update it. Despite a significantly better performance of transfusion services with a TC, the use of these charts is low even in these services.

Failure to comply with good technical practices, which are required by Hemominas, was also identified. The signing of the transfusion book by the person responsible, which was significantly lower in transfusion services without a TC, was observed in less than half the services with a TC. High rates of non-compliance of the requirements of Hemominas were also observed in terms of deletions in transfusion requests and the presence of a clinical pathology technician to perform pre-transfusion tests.

Decision tree analysis demonstrated a correlation between the presence of a TC and compliance with current technical standards, in particular with aspects of blood transfusion surveillance such as the notification and investigation of the causes of transfusion reactions and the presence and update of individual transfusion charts, suggesting greater concern of these services with transfusion monitoring. However, despite some advances, the performance of TCs is still incipient and the action of these committees should be better organized and more effective in order to promote a better control of the transfusion process and, consequently, to minimize risks.

The present study analyzed aspects of transfusion practice that are regulated by current legislation. Compliance with these aspects is mandatory (correct identification of recipient samples, existence of an individual transfusion chart for each recipient, a correctly and completely filled out transfusion request) and is the responsibility of the technician of the transfusion center. The person responsible should guarantee compliance with these requirements since these measures, complemented by the TC, will contribute to minimize transfusion reactions and to facilitate their screening and identification. The present data will enable state health surveillance agencies and Hemominas, as well as other government and public organs, to adopt more effective strategies to inspect services and implement actions to improve transfusion safety. These measures should not only address the implementation of TCs at all hospitals that use blood products, but also a more effective participation of these committees in the blood transfusion practices of health services.

\section{References}

1. Andreu G, Morel P, Forestier F, Debeir J, Rebibo D, Janvier G, et al. Hemovigilance network in France: organization and analysis of immediate transfusion incident reports from 1994 to 1998. Transfusion. 2002;42(10):1356-64. Comment in: Transfusion. 2002;42(10):1249-52.

2. Haynes SL, Torella F. The role of hospital transfusion committees in blood product conservation. Transfus Med Rev. 2004;18(2):93-104.

3. Morel P, Hervé P. Surveillance of blood transfusion safety: contribution of the hemovigilance strategy in France. Transfus Med Rev. 1998;12(2):109-27.

4. Stainsby D, Jones H, Asher D, Atterbury C, Boncinelli A, Brant L, Chapman CE, Davison K, Gerrard R, Gray A, Knowles S, Love EM, Milkins C, McClelland DB, Norfolk DR, Soldan K, Taylor C, Revill J, Williamson LM, Cohen H; SHOT Steering Group. Serious hazards of transfusion: a decade of hemovigilance in the UK. Transfus Med Rev. 2006;20(4):273-82.

5. Williamson LM, Love EM. Reporting serious hazards of transfusion: the SHOT program. Transfus Med Rev. 1998;12(1):28-35.

6. Hervé P, des Floris MF, Rebibo D, Morei P, Andreu G. Hemovigilance in France. Rev Bras Hemat Hemoter. 2000;22(3):368-73

7. Proietti AB, Cioffi J. Hemovigilância: verificação final da qualidade da transfusão? Rev Bras Hematol Hemoter. 2008;30(3):173-4.

8. Henneman EA, Avrunin GS, Clarke LA, Osterweil LJ, Andrzejewski $\mathrm{C} \mathrm{Jr}$, Merrigan $\mathrm{K}$, et al. Increasing pacient safety and efficiency in transfusion therapy using formal process definitions. Transfus Med Rev. 2007;21(1):49-57.

9. Hergon E, Moutel G, Duchange N, Bellier L, Rouger P, Hervé C. Risk management in transfusion after the HIV blood contamination crisis in France: the impact of the precautionary principle. Transfus Med Rev. 2005;19(4):273-80.

10. Kleinman S, Chan P, Robillard P. Risks associated with transfusion of cellular blood components in Canada. Transfus Med Rev. 2003;17(2):120-62.

11. Sajwani FH. Improving blood transfusion practice by regular education in the United Arab Emirates. Transfusion. 2012;52(7 Pt 2):1628-31.

12. Jimenez MT, Pineda A. Comitê transfusional hospitalario: auditoría de la practica transfusional. Rev Argent Transf. 2001;27(4):365-81. 
13. Brener S, Carvalho RV, Ferreira AM, Silva MM, Valle MC, Moraes-Souza H. Physical and operational infrastructure of transfusion services of the public blood bank network in the State of Minas Gerais, Brazil, 2007/2008. Rev Bras Hematol Hemoter. 2010;32(6):455-62.

14. Kleinman S, Chan P, Robillard P. Risks associated with transfusion of cellular blood components in Canada. Transf Med Rev. 2003;17(2):120-62.

15. Brasil. Ministério da Saúde. Agência Nacional de Vigilância Sanitária. Dados sobre produção e transfusão de hemocomponentes . Boletim de Hemovigilância [Internet] $\mathrm{n}^{\circ}$ 3. Brasilia (DF): Ministério da Saúde; 2010. 20 p. [cited 2011 Set 15]. Available from: http://portal.anvisa.gov. $\mathrm{br} / \mathrm{wps} / \mathrm{wcm} /$ connect $/ 2385 \mathrm{~d} 400474580 \mathrm{fb} 8 \mathrm{~d} 0 \mathrm{add} 3 \mathrm{fbc} 4 \mathrm{c} 6735 /$ boletim hemovigilancia.pdf?MOD=AJPERES

16. Brasil. Ministério da Saúde. Agência Nacional de Vigilância Sanitária. Resolução 153 de 14 de junho de 2004. Determina o regulamento técnico para os procedimentos hemoterápicos, incluindo a coleta,o processamento, a testagem, o armazenamento, o transporte, o controle de qualidade e o uso humano de sangue e seus componentes, obtidos do sangue venoso, do cordão umbilical, da placenta e da medula óssea [Internet]. Brasília (DF): ANVISA; 2004. [cited 2006 Nov 21]. Available from: http://portal.saude. gov.br/portal/arquivos/pdf/resolucao_153_2004.pdf
17. Brasil. Ministério da Saúde. Agência Nacional de Vigilância Sanitária. Manual técnico de hemovigilância - identificação de reações transfusionais imediatas e tardias não infecciosas [Internet]. Brasília (DF): ANVISA; 2007. [cited 2008 Jun 21]. Available from: http://portal.anvisa.gov.br/ wps/wcm/connect/17386000474581698db3dd3fbc4c6735/manual_ tecnico_hemovigilancia_08112007.pdf?MOD=AJPERES

18. Breiman L, Friedman J, Olshen R, Stone C. Classification and regression trees. New York: Chapman \& Hall; 1993.

19. Covas DT, Langhi Júnior DM, Bordin JO. Hemoterapia: fundamentos e prática. São Paulo: Atheneu; 2007. 658 p.

20. Alter HJ, Klein HG. The hazards of blood transfusion in historical perspective. Blood. 2008;112(7):2617-25.

21. Brasil. Ministério da Saúde, Agência Nacional de Vigilância Sanitária. Sistema de vigilância pós-uso e pós-comercialização de produtos e serviços para a saúde e do sistema de hemovigilância. Boletim de Hemovigilância [Internet] nº2. Brasília (DF): Ministério da Saúde 2009 16 p. [cited 2010 Nov 26]. Available from: http://portal.anvisa.gov. $\mathrm{br} / \mathrm{wps} / \mathrm{wcm} / \mathrm{connect} / 3 \mathrm{a} 17 \mathrm{a} 980474585998 \mathrm{f} 47 \mathrm{df3fbc} 4 \mathrm{c} 6735 /$ boletim hemo_2009.pdf?MOD=AJPERES 